\title{
IMPROVING THE RECYCLING RATE OF THE CONSTRUCTION INDUSTRY
}

K. Grigoriadis ${ }^{1}$, M. Whittaker ${ }^{1}$, M. Soutsos ${ }^{1}$, W. Sha ${ }^{1}$, L. Napolano ${ }^{2}$, A. Klinge ${ }^{3}$, S. Paganoni $^{3}$, M. Casado ${ }^{4}$, L. Brander ${ }^{5}$, M. Prieto Rabade ${ }^{5}$, U. Mueller ${ }^{5}$, M. Mousavi $^{5}$, O.

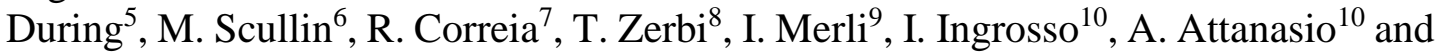
A. Largo $^{10}$

${ }^{1}$ School of Natural and Built Environment, Queen's University, Belfast, UK

${ }^{2}$ STRESS S.C.AR.L., Naples, Italy

${ }^{3}$ ZRS Architekten Ingenieure GmbH, Berlin, Germany

${ }^{4}$ ACCIONA Construction Technology Centre, Madrid, Spain

${ }^{5}$ RISE, Boras, Sweden

${ }^{6} \mathrm{CDE}$ Global Ltd, Cookstown, UK

${ }^{7}$ CREAGH Concrete, Toomebridge, UK

${ }^{8}$ STAM S.R.L., Genoa, Italy

${ }^{9}$ VORTEX HYDRA S.R.L., Ferrara, Italy

${ }^{10}$ CETMA, Brindisi, Italy

\begin{abstract}
Construction and Demolition Waste (CDW) accounts for approximately 25-30\% of all waste generated across Europe each year. However, Waste Framework Directive 2008/98/EC requires from all EU member states to achieve at least $70 \%$ re-use, recycling or other recovery of non-hazardous CDW by 2020. In response, the Horizon $2020 \mathrm{RE}^{4}$ Project (REuse and REcycling of CDW materials and structures in energy efficient pREfabricated elements for building REfurbishment and construction) consortium was set up. Its main aims are to assess the quality of various CDW fractions (e.g. mineral aggregate, timber, plastics, silt \& clay), improve the quality of mineral aggregates and develop different building elements/components which contain at least $65 \%$ of CDW. Innovative building concepts will also be developed in an effort to improve recycling rates of future buildings through the use of prefabrication and modular design. The developed products and technologies will be assessed in a number of test sites by building 2 -storey demonstration houses.
\end{abstract}

Keywords: CDW-derived materials, Prefabricated structures, Recycling, Reuse 


\section{INTRODUCTION}

Construction and Demolition Waste (CDW) consists of a heterogeneous mix of materials such as concrete, mortar, mineral aggregates, bricks, tiles, bitumen, ferrous, plastic, wood and organic lightweight particles (European Commission, 2016). Each year more than 800 million tonnes of CDW (including excavated soil) are generated across EU (European Commission, 2017). The vast amount of CDW is deposited to landfills since most existing buildings were not designed for easy disassembly and reuse (Sassi, 2002). In addition, most recovered CDW is confined to low grade applications (e.g. recycled aggregate used for pipe bedding or subbase and base course in road pavement construction) despite the fact that some of its constituents have a high resource value. However, EU Waste Framework Directive 2008/98/EC (European Commission, 1998) requires from all member states to achieve at least $70 \%$ re-use, recycling or other recovery of non-hazardous CDW by 2020. Consequently, the development of reliable strategies and innovative technologies is required in order to:

- Promote the use of CDW-derived materials in high grade applications

- Increase the percentage of CDW-derived materials in new prefabricated building elements and components

- Reduce the amount of future CDW coming from the next generation of buildings

- Reduce construction industry's $\mathrm{CO}_{2}$ footprint

- Reduce consumption of natural resources

The above challenges can be met by adopting a number of Best Environmental Management Practices (BEMP) such as: (a) CDW management plans, (b) economic instruments, (c) site waste prevention and logistics strategies, (d) prevention and collection, (e) site waste management plans, (f) Efficient use of materials, (g) building deconstruction, (h) re-use of materials, (i) waste treatment and material recovery, (j) quality assurance schemes and $(\mathrm{k})$ recycling and recovery of gypsum plasterboards (Galvez-Martos et al., 2018).

CDW processing and recycling techniques significantly evolved over the last few decades. However, the nature of the final CDW-derived materials and their market value vary significantly. A typical CDW treatment plant will mainly produce mineral aggregate while other types of CDW such as metals, wood, glass and plastics require further treatment. From well sorted CDW, good quality coarse recycled aggregates can be produced, which can then be used in high grade applications such as partial replacement of virgin aggregate in structural concrete (Wijayasundara, Mendis \& Crawford, 2017), (Wijayasundara, Mendis \& Crawford, 2018), (Galvez-Martos et al., 2018).

This paper aims to provide an outline of the efforts of the $\mathrm{RE}^{4}$ project ( $\mathrm{RE}^{4}$ project, 2018) consortium in developing prefabricated building elements (structural and nonstructural) and components which incorporate at least $65 \%$ by weight of $\mathrm{CDW}$-derived materials. In addition, it provides information on the use of these products for building 
a 2-storey demonstration residential building in two different locations plus refurbishing an existing one in a third location across Europe. Finally, it describes the Life Cycle Sustainability Assessment (LCSA) methods to be used for evaluating some of the above developed prefabricated products.

\section{BENEFITS OF PREFABRICATION AND MODULAR DESIGN}

\section{Prefabrication}

Prefabricated elements and components differ from the ones made on-site as the former are manufactured under factory conditions and then transported to construction sites. This has many benefits such as better quality control, shorter construction times, reduced costs, reduced site disruption (i.e. less noise, pollution and waste) and improved health and safety conditions for construction workers and local residents (NHBC Foundation, 2016), (NHBC Foundation, 2018).

\section{Modular Design}

In addition to the development of building elements (structural and non-structural) containing large amounts of CDW-derived materials, the prefabricated elements are designed for re-use at the end of their design life. To achieve this, the designed buildings within the scope of $\mathrm{RE}^{4}$ are to be modular, where each 'module' (beam, column, slab, façade panel, etc.) can be removed and re-used later in its design life. This presents a series of challenges which include the following:

- Ensuring all elements and components comply with existing structural design codes and building regulations

- Using reversible mechanical connections for easy assembly and disassembly

- Limiting the size of elements and components for standard lorry delivery to site

- Ensuring ease of maintenance, repair or replacement

- Developing a Building Information Modelling (BIM)-compatible tool for CDW estimation and management

All developed elements/components were deemed suitable for modular design. Foundations did not form part of this study as these are typically cast in-situ.

\section{INCREASING THE \% OF REUSED AND RECYCLED CDW}

The use of CDW-derived aggregates in concrete, for example, is already permitted and standardised. Currently, EN 206 (2013+A1:2016) and EN 12620 (2013) limit the maximum amount of coarse recycled aggregates up to $50 \%$, depending on exposure conditions. However, this limits the recycling potential of CDW. Raw CDW first needs to be treated in order to become suitable for use as recycled aggregate. This involves removing defective particles such as floating particles, clay and soil, ferrous metals and gypsum. However, to increase the recycling rate, the amount of fractions such as 
ceramics (bricks \& tiles), bitumen, glass, and non-floating wood present in treated recycled aggregate must also be reduced (Figure $1 \mathrm{a}-\mathrm{b}$ ).

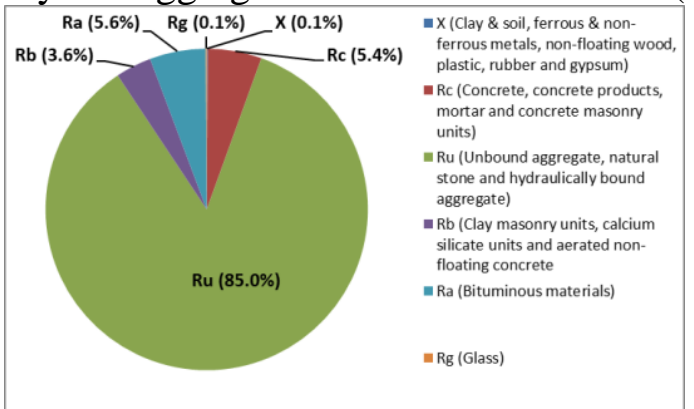

a) Northern Europe recycled aggregate

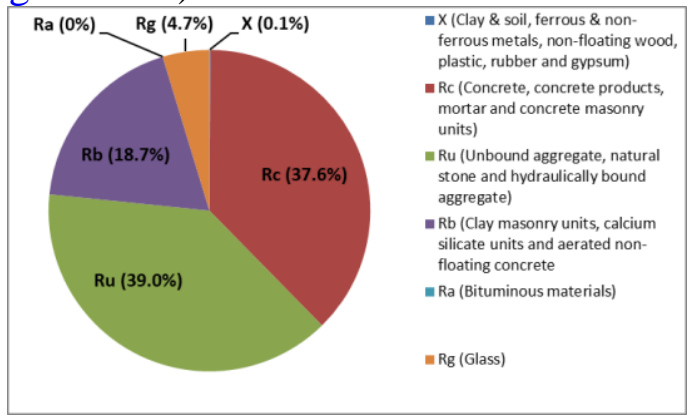

b) Southern Europe recycled aggregate

Figure $1(\mathrm{a}-\mathrm{b})$. Typical composition of $8-16 \mathrm{~mm}$ processed recycled aggregate

\section{Improving the Quality of CDW Aggregates}

To further increase recycling rates, attempts have been made to improve the quality of the CDW aggregates.

For fine aggregates $(\leq 2 \mathrm{~mm})$, sand obtained after wet processing of CDW is dewatered and fed into a series of attrition cells (at $80 \%$ solids concentration) where it is scrubbed clean (Figure 2 a). Next, the sand is separated based on density. This is done by diluting the sand with water and pump it to the top of a spiral separation column (Figure $2 \mathrm{~b}$ ). As the sand flows through the spiral column, lighter particles tend to migrate towards its outer edge, whereas heavier particles remain close to the centre of the column. When the particles reach the bottom of the column, they are collected and separated by density to the user's requirements.

For coarse aggregates ( $\geq 8 \mathrm{~mm}$ ), a fully automated robotic sorting system (Figure $2 \mathrm{c}$ ) has been developed for removing the remaining defective particles (bricks, tiles, plastics, glass, non-floating wood etc.). These particles are detected on a real time basis using advanced optical and electronic equipment which employs Near Infra-red (NIR) Reflectance Spectroscopy. The defective particles are then removed using a robotic arm. Currently, the production rate stands at $100 \mathrm{~kg} / \mathrm{h}$.

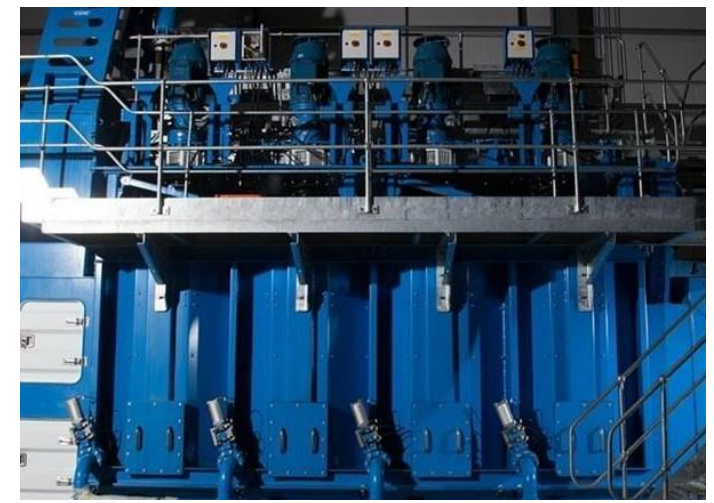

a) Attrition cells

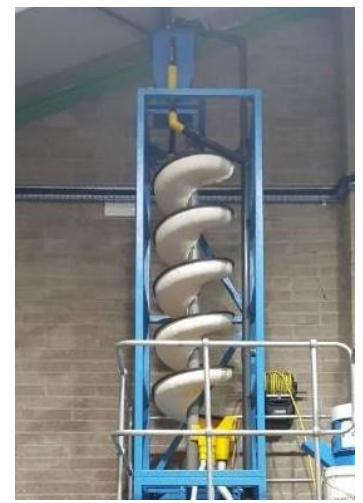

b) Spiral separation column 


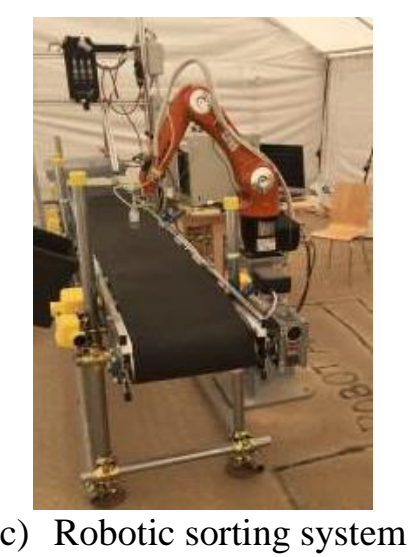

Figure 2 (a-c). Examples of new technologies used for improving CDW-derived mineral fractions.

\section{Valorisation of Ceramic Fraction}

In order to avoid disposal of the ceramics fraction successfully removed from the CDW waste stream, two potential uses were investigated. Initially, bricks and tiles were ground to a fine powder to be used as a precursor for the development of Portland Cement-free binders. The fine powder was then activated using sodium oxide $\left(\mathrm{Na}_{2} \mathrm{O}\right)$ and sodium silicate $\left(\mathrm{Na}_{2} \mathrm{SiO}_{3}\right)$ solutions (Reig et al., 2013), (Komnitsas et al., 2015), (Robayo-Salazar, Rivera \& Mejia de Gutierrez, 2017), (Wong et al., 2018). The water/binder (w/b) ratio of all mixes was fixed at 0.37 . Depending on the concentration of the activating solutions, mortar samples reached compressive strength values of up to $30 \mathrm{MPa}$ at 28 days.

The use of ceramics in the manufacture of floor and wall tiles was also investigated. This was achieved by mixing the fine ceramic powder with resin and then allow it to harden inside moulds. The grading of the ceramic powder and the resin/ceramic powder ratio were investigated to achieve the desired workability and strength values. The optimised mix recipe was evaluated in terms of its physical (water absorption) and mechanical (flexural and compressive strength) performance.

\section{RECYCLING AND USE OF CDW IN STRUCTURAL ELEMENTS}

\section{Concrete}

Concrete was chosen as the main material for designing structural elements such as beams, columns, slabs and sandwich panels due to its versatility, immense strength, performance and cost. The types of concrete developed are shown in Table 1 and include 2 types of concrete mixes: vibrated (Figure 3 a) and self-compacted (Figure 3 b). After casting a number of trial mixes, the developed concretes achieved the required fresh, hardened and durability properties set by the manufacturers within the Project. Virgin aggregate replacement varied between $40 \%$ and $100 \%$ depending on the size and source of the recycled aggregate and the type of developed concrete. 
Table 1. Different types of structural concrete incorporating high levels of CDW.

\begin{tabular}{|l|c|c|c|}
\hline $\begin{array}{c}\text { Type of } \\
\text { structural } \\
\text { concrete }\end{array}$ & Consistency class & Strength class & $\begin{array}{c}\text { Virgin aggregate } \\
\text { replacement level } \\
\text { (\%) }\end{array}$ \\
\hline Vibrated & $\begin{array}{c}\mathrm{S} 3 \\
\text { (slump test) }\end{array}$ & $\mathrm{C} 32 / 40$ & 83 \\
\cline { 2 - 4 } & $\begin{array}{c}\mathrm{S} 2 / \mathrm{S} 3 \\
\text { (slump test) }\end{array}$ & $\mathrm{C} 25 / 30$ & 100 \\
\hline Self-compacted & $\begin{array}{c}\text { 640-770 mm } \\
\text { (slump flow test) }\end{array}$ & $\mathrm{C} 40 / 50$ & $40-80$ \\
\hline
\end{tabular}

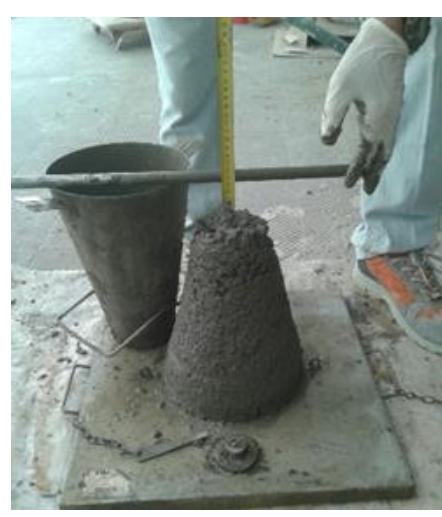

a) Vibrated concrete

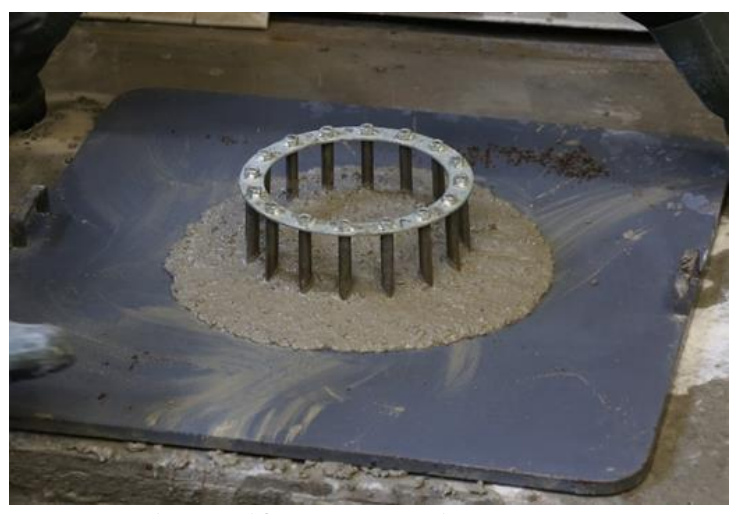

b) Self-compacted concrete

Figure 3 (a-b). Development of vibrated and self-compacted concrete.

\section{Reclaimed Timber}

A complete methodology for making structural and non-structural elements from CDW timber was developed. Different methods for the procurement and characterisation of CDW timber were used to obtain raw materials that can be strength graded according to existing European norms and national standards.

As a precondition, CDW timber must be free from wood paints and preservatives, fungal/insect infestation and other forms of serious damage. The absence of wood paints and preservatives needs to be verified by an accredited laboratory, whereas infected or damaged areas need to be identified and removed.

On-site visual inspection is usually employed to determine the existence and extent of fungal/insect infestation and/or other forms of damage. In addition, it is used to determine the nature and moisture content of CDW timber. Literature data on the other hand, can be used to estimate the raw density of CDW timber in case no information is available regarding its origin. Next, impurities and foreign objects (e.g. metal fittings and preservatives) must be removed for assessing CDW timber in terms of dimensions, location of cracks and slope of grain. Timber elements are then cut or planed to standard cross-section sizes in accordance with DIN 4074-1 (2012). This in turn, leads to the respective strength class in accordance with EN 338 (2016). The above procedure enables the effective re-use and recycling of CDW timber with minimal loss in performance for making new structural elements (Cavalli et al., 2016). 
Depending on the nature of the CDW timber element, its state of conservation and final strength grade, several strategies can be adopted for its re-use as shown below:

- Complete re-use of the CDW timber element using minimum amount of processing

- Processing which leads to standard-size cross-sections (

- Figure 4 a and b)

- Glulam finished product

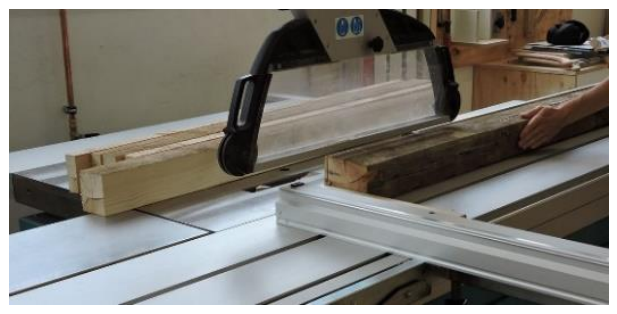

a) Processing of salvaged timber

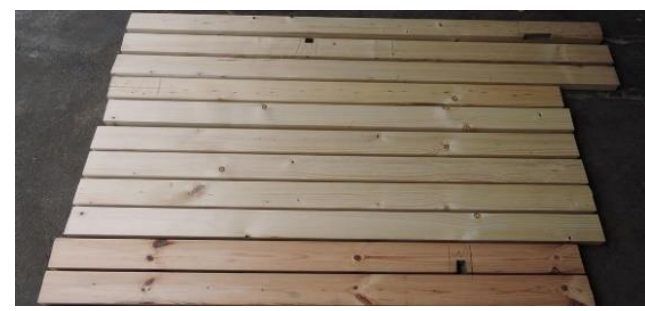

b) Cut and planned lamellas

Figure 4 (a-b). Processing of salvaged timber beams into standard-size cross-sections.

In the case of glulam timber beams, a characteristic bending strength of $24 \mathrm{MPa}$ (i.e. glulam strength class GL24) should be reached in accordance with EN 14080 (2013). If CDW timber is deemed not to be suitable for use in structural elements, then it can still be recycled and used for making non-structural elements (e.g. cladding or wood fibre insulation). Because of its versatility and potential use as raw material for making a large number of structural and non-structural elements, the recycling rate of CDW timber is very high.

\section{RECYCLING AND USE OF CDW IN NON-STRUCTURAL ELEMENTS AND COMPONENTS}

\section{CDW Mineral Aggregate for the Production of Building Blocks}

A semi-dry concrete mix was developed for making building blocks to be used in nonstructural elements such as internal partitions and external non-load bearing walls. Net dry density $\left(2000 \mathrm{~kg} / \mathrm{m}^{3}\right)$ and compressive strength (7.3 MPa at 28 days) were used as performance indicators (Concrete Block Association, 2017). Full replacement of virgin aggregate by CDW aggregate was achieved, while complying with fresh density and compressive strength requirements. However, for environmental and financial reasons (i.e. increase in the amount of Portland cement used in the mix for maintaining the required strength) the replacement level of virgin aggregate by CDW aggregate was set at $70 \%$.

\section{CDW Mineral Aggregate for the Production of Roof Tiles}

The substitution of virgin aggregates by CDW mineral aggregates was also investigated in extruded tiles. The extrusion process was based on the use of fine 
mineral aggregate $(0-2 \mathrm{~mm})$ and a CEM II/B-LL $32.5 \mathrm{R}$ cement. By replacing $50 \%$ of the virgin aggregates with mineral $\mathrm{CDW}$, a mix prepared with 1-part cement and 3parts sand, with a w/b ratio of 0.3 satisfied all requirements set by relevant standards.

\section{Lightweight Particles for the Production of Insulating Concretes}

Used lightweight CDW particles were small in size $(\leq 4 \mathrm{~mm})$ and were made of rigid plastics or mixed wood/plastics. $\mathrm{RE}^{4}$ attempted to utilise these fractions in the development of insulating concretes having low thermal conductivity.

The target properties used for the development of lightweight Portland Cement (PC) concrete and the optimised mixes meeting those targets are shown in Table 2. Depending on the source, rigid plastics or mixed wood/plastics could replace up to $70 \%$ and $50 \%$ of the natural fine aggregate fraction, respectively.

Table 2. Performance of developed lightweight insulating mortars

\begin{tabular}{|l|c|c|c|}
\hline $\begin{array}{l}\text { Fresh and hardened (28 days) } \\
\text { properties of lightweight } \\
\text { concrete }\end{array}$ & $\begin{array}{c}\text { Target } \\
\text { application }\end{array}$ & \multicolumn{2}{|c|}{$\begin{array}{l}\text { Performance of developed } \\
\text { lightweight concretes }\end{array}$} \\
\cline { 2 - 4 } & Panel layers & $\begin{array}{c}\text { Rigid } \\
\text { plastics }\end{array}$ & $\begin{array}{c}\text { Mixed } \\
\text { wood/plastics }\end{array}$ \\
\hline Consistency class (slump test) & $\mathrm{S} 4$ & $\mathrm{~S} 4 / \mathrm{S} 5$ & $\mathrm{~S} 5$ \\
\hline Hardened density $\left(\mathrm{kg} / \mathrm{m}^{3}\right)$ & $800-1400$ & 1260 & 1250 \\
\hline Compressive strength $(\mathrm{MPa})$ & $4.5-24.0$ & 7.5 & 4.5 \\
\hline Thermal conductivity $(\mathrm{W} / \mathrm{mK})$ & $0.16-1.00$ & 0.31 & 0.29 \\
\hline
\end{tabular}

\section{Lightweight Particles for the Production of Insulation Panels}

Lightweight particles i.e. rigid plastics and wood scraps were also used for making insulation panels.

For panels made using rigid plastics, the plastic particles were mixed with polyurethane (PU) foam, already a well-established insulation material. The plastic particle content of the mix was varied from $5 \%$ to $50 \%$ by volume to create panels of different density values. Best performance in terms of density and thermal conductivity values was observed when the plastic content was set at $5 \%$.

For panels made using wood fibres, a wet process was implemented. The wood was first soaked in water. Next, it was compacted into moulds and kept under high pressure and temperature (autoclave) until it was dried. To improve their fire resistance, prior to making the panels, the wood was mineralised by injecting a $\mathrm{MgO}$ solution into it under a pressure of 8 bar. Based on the temperature and duration of the manufacturing process adopted, wood panels were classified into 3 different apparent density classes $\left(215 \pm 10 \mathrm{~kg} / \mathrm{m}^{3}, 300 \pm 10 \mathrm{~kg} / \mathrm{m}^{3}\right.$ and $\left.325 \pm 10 \mathrm{~kg} / \mathrm{m}^{3}\right)$.

\section{DEMONSTRATION BUILDINGS}

Two sites across Europe (Northern Ireland and Spain) have been identified between Project partners to be used for constructing full-scale 2-storey demonstration 
residential buildings. Table 3 provides details of the elements to be used in the construction of the above demonstration buildings.

Table 3. Types of elements (structural and non-structural) and components to be used in the construction of 2-storey demonstration residential buildings.

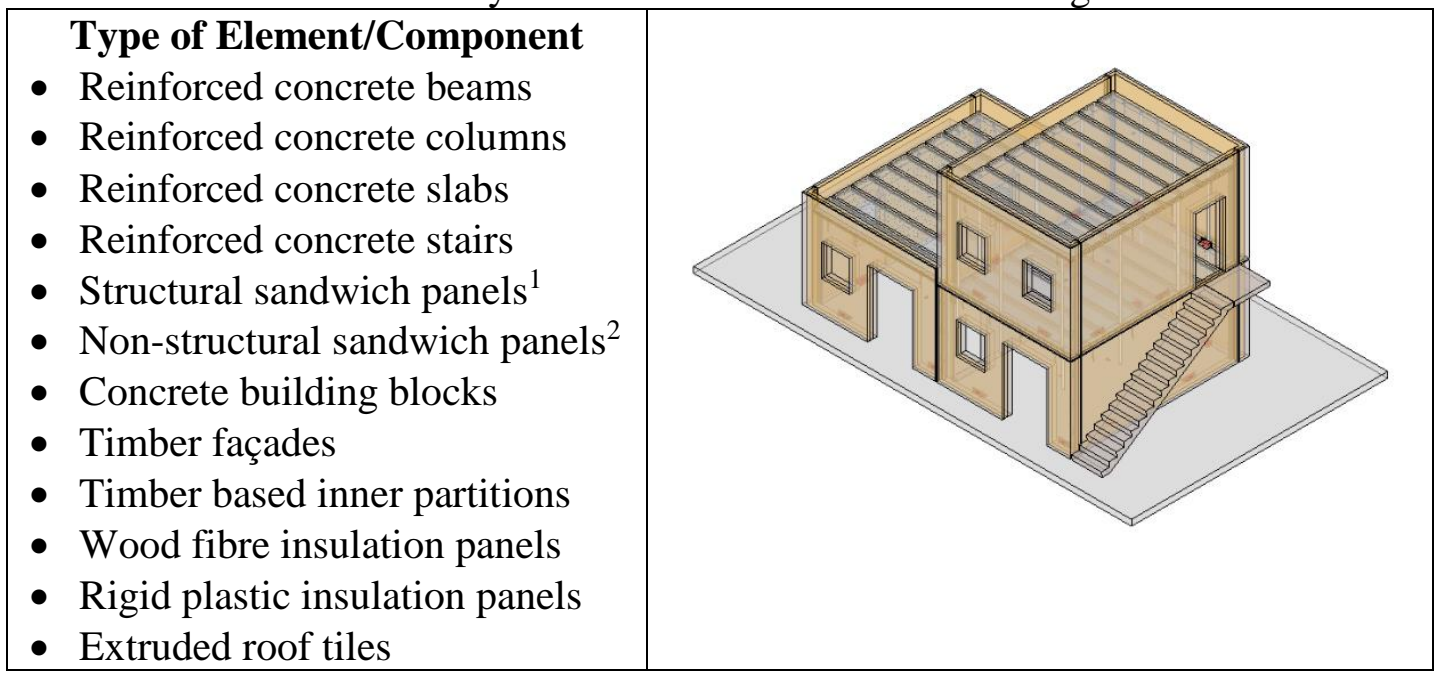

1. Structural sandwich panels consist of two layers of steel reinforced C40/50 self-compacted concrete and a layer of PIR insulation.

2. Non-structural sandwich panels consist of one layer of steel reinforced C40/50 self-compacted concrete, one layer of PIR insulation and one layer of textile reinforced high performance concrete.

In addition to the above 2 sites, a third demonstration site in Italy will be used to evaluate the thermal performance of a ventilated façade developed for use in refurbishment projects.

\section{LIFE CYCLE SUSTAINABILITY ASSESSMENT (LCSA)}

$\mathrm{RE}^{4}$ project aims to provide a comprehensive strategy for the sustainable management and use of CDW as raw material in the development of prefabricated elements (structural and non-structural) and components. It aims to reduce $\mathrm{CO}_{2}$ emissions (by at least 30\%), create energy savings (by at least 20\%), improve resource efficiency (developed products containing at least $65 \%$ by weight of CDW-derived materials), generate less waste (thanks to elements designed for easy disassembly at the end of their design life) and reduce the amount of CDW deposited to landfills (thanks to improved recycling/reuse rates).

Life Cycle Sustainability Assessment (LCSA) methods will be employed for performing a sound verification of the obtained results. During application of LCSA, all environmental, social and economic impacts and/or benefits of the developed $\mathrm{RE}^{4}$ products throughout their life cycle will be taken into account and compared against benchmark commercial products. More specifically, the main challenge of $\mathrm{RE}^{4}$ project will be to define the individual environmental, economic and social impacts of developed elements as well as an innovative method for integrating all the above results. The latter task will be performed through the definition of a framework for 
LCSA, which will combine the results of the Environmental Life Cycle Assessment (E-LCA), Social Life Cycle Assessment (S-LCA) and Life Cycle Costing (LCC). In this regard, LCSA can be used as a guide by construction industry stakeholders for conducting sustainability comparisons between different types of prefabricated systems.

LCSA will be performed on 6 different types of $\mathrm{RE}^{4}$ building elements (structural and non-structural). Each element will be compared against a reference state-of-the-art conventional element. Both $\mathrm{RE}^{4}$ and conventional elements have been designed taking into account the different energy requirements of the 3 demonstration sites which are determined by Northern or Southern Europe climatic conditions. The $\mathrm{RE}^{4}$ elements to be evaluated consist of the following:

- Timber non-load bearing façade panel (designed for warm climatic conditions)

- Timber non-load bearing façade panel (designed for cold climatic conditions)

- Sandwich load-bearing panel (designed for cold climatic conditions)

- Sandwich non-load bearing panel (designed for warm climatic conditions)

- Timber based internal partition wall

- Ventilated façade to be used in refurbishment projects (designed for warm climatic conditions)

Table 4 provides details of the above 6 types of elements to be used for performing the LCSA. 
Table 4. Details of $\mathrm{RE}^{4}$ developed elements used for performing LCSA

\begin{tabular}{|c|c|}
\hline Type of Element & Description/Functional Unit/System Boundaries ${ }^{1}$ \\
\hline 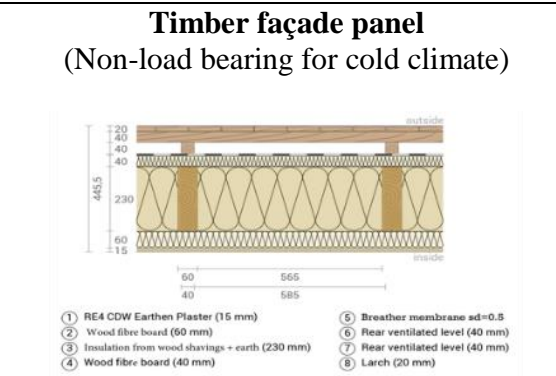 & $\begin{array}{l}\text { Description: Timber studs, top and bottom plates, } \\
\text { weatherboards, wood fibre insulation and wood fibre boards are } \\
\text { made of reused or recycled timber. Earth plaster is made of } \\
\text { CDW sand and virgin clayey soil (binder). Due to the use of } \\
\text { reversible connections the façade can be fully reused. } \\
\text { Functional Unit: } \mathrm{m}^{2} \text { of panels with the same thermal } \\
\left.\text { transmittance (U-value: } 0.14 \mathrm{~W} / \mathrm{m}^{2} \mathrm{~K}\right) \text {. }\end{array}$ \\
\hline 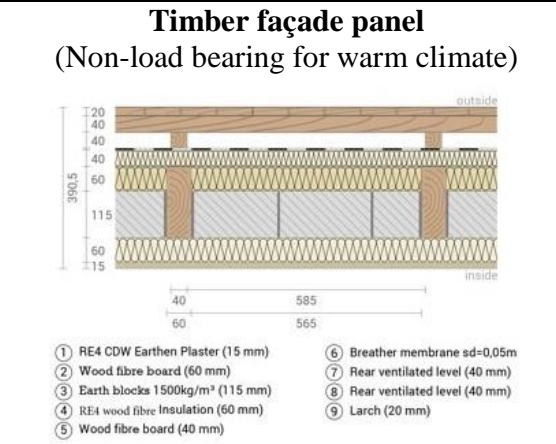 & $\begin{array}{l}\text { Description: Timber studs, top and bottom plates, } \\
\text { weatherboards, wood fibre insulation and wood fibre boards are } \\
\text { made of reused or recycled timber. Commercial earth blocks are } \\
\text { used to increase the performance during summer months. Earth } \\
\text { plaster is made of CDW sand and virgin clayey soil (binder). } \\
\text { Due to the use of reversible connections the façade can be fully } \\
\text { reused. } \\
\text { Functional Unit: } \mathrm{m}^{2} \text { of panels with the same thermal } \\
\text { transmittance (U-value: } 0.25 \mathrm{~W} / \mathrm{m}^{2} \mathrm{~K} \text { ). }\end{array}$ \\
\hline 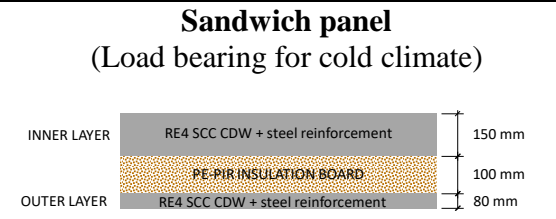 & $\begin{array}{l}\text { Description: CDW-derived aggregates and Portland cement are } \\
\text { used in the manufacture of inner and outer concrete layers of } \\
\text { sandwich panel. PE-PIR insulation material is used. Due to the } \\
\text { use of reversible connections the panel can be fully reused. } \\
\text { Functional Unit: } \mathrm{m}^{2} \text { of panels with the same thermal } \\
\left.\text { transmittance (U-value: } 0.21 \mathrm{~W} / \mathrm{m}^{2} \mathrm{~K}\right) \text {. }\end{array}$ \\
\hline 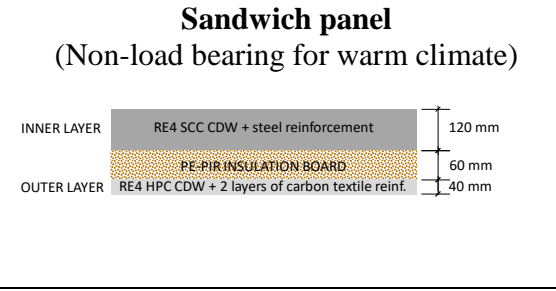 & $\begin{array}{l}\text { Description: CDW-derived aggregates are used in the } \\
\text { manufacture of inner and outer concrete layers of sandwich } \\
\text { panel. Partial replacement of Portland cement in the concrete } \\
\text { mix by fly-ash, limestone and silica fume. PE-PIR insulation } \\
\text { material is used. Due to the use of reversible connections the } \\
\text { panel can be fully reused. } \\
\text { Functional Unit: } \mathrm{m}^{2} \text { of panels with the same thermal } \\
\text { transmittance (U-value: } 0.34 \mathrm{~W} / \mathrm{m}^{2} \mathrm{~K} \text { ). }\end{array}$ \\
\hline 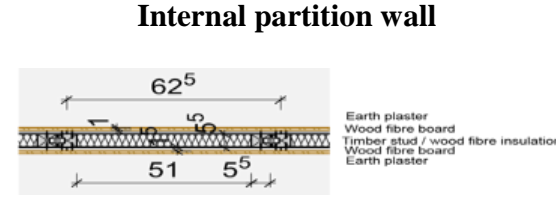 & $\begin{array}{l}\text { Description: Timber studs, wood fibre insulation and wood } \\
\text { fibre boards are made of reused/recycled timber. Plaster is made } \\
\text { of CDW sand and virgin clayey soil (binder). Reuse of all } \\
\text { components mainly due to the reversible connections. } \\
\text { Functional Unit: } \mathrm{m}^{2} \text { of internal partition walls with the aim of } \\
\text { separating two rooms. }\end{array}$ \\
\hline $\begin{array}{l}\text { Ventilated façade } \\
\text { (Warm climate) }\end{array}$ & $\begin{array}{l}\text { Description: Wood fibre insulation and tiles are obtained from } \\
\text { the processing of CDW. Due to the use of reversible connections } \\
\text { all components can be reused. } \\
\text { Functional Unit: } \mathrm{m}^{2} \text { of façades with the same thermal } \\
\text { transmittance (U-value: } 0.34 \mathrm{~W} / \mathrm{m}^{2} \mathrm{~K} \text { ). }\end{array}$ \\
\hline
\end{tabular}


1. The following System boundaries are used for all developed elements under consideration: manufacturing, transportation, to building site, installation, maintenance, deconstruction and reuse/recycling.

\section{CONCLUSIONS}

The main aim of $\mathrm{RE}^{4}$ project is the development of prefabricated building elements (structural and non-structural) and components which incorporate at least $65 \%$ of CDW-derived materials. In order to achieve the above target, new technologies had to be developed for improving the treatment process of raw CDW and hence the quality of CDW-derived materials. A comprehensive testing regime was then used to ensure that CDW-derived materials comply with existing European structural design norms and national building codes regarding their physical, mechanical and durability properties. Next, a large number of building elements and components was developed based on the above CDW-derived materials. In addition, modular design of developed elements and components was employed to ensure ease of reuse and recycling at the end of their design life. Over the coming months, a comprehensive LCSA will be performed on a number of selected elements with the aim of quantifying the environmental, social and financial benefits of the above approach. Next, full-size elements and components will be made and evaluated by building a number of 2-storey demonstration residential buildings in Northern Ireland and Spain. Following this, a definition of quality classes of CDW-derived materials for use in different applications will take place. Developed quality classes can then be included in updated versions of structural design norms and building codes leading to a wider use of CDW-derived materials by the construction industry. Consequently, reducing the amount of CDW coming from the next generation of buildings.

\section{ACKNOWLEDGEMENTS}

The authors gratefully acknowledge the funding provided by the European Commission Horizon 2020 Framework Programme for financing this research for $\mathrm{RE}^{4}$ project (Grant No: 723583).

\section{REFERENCES}

Cavalli, A., Cibecchini, D., Tongi M. and Sousa, H.S. (2016). "A review on the mechanical properties of aged wood and salvaged timber." Con. Build. Mater. 114,681-687.

Concrete Block Association (2017). Aggregate Concrete Blocks. Data Sheet 1: A guide to selection and specification. Leicester, UK.

German Institute for Standardization (2012). DIN 4074-1:2012. Strength grading of wood. Part 1: Coniferous sawn timber. Berlin, Germany

European Commission (1998). Directive 2008/98/EC On Waste and Repealing Certain Directives. Brussels, Belgium. 
European Commission (2016). EU Construction and Demolition Waste Management Protocol. Brussels, Belgium.

European Commission (2017). Resource Efficient Use of Mixed Wastes - Improving Management of Construction and Demolition Waste - Final Report. Brussels, Belgium.

European Committee for Standardization (2016). EN 206:2013+A1:2016. Concrete. Specification, performance, production and conformity. Brussels, Belgium.

European Committee for Standardization (2016). EN 338:2016. Structural timber. Strength classes. Brussels, Belgium.

European Committee for Standardization (2013). EN12620:2013. Aggregates for concrete. Brussels, Belgium.

European Committee for Standardization (2013). EN 14080:2013. Timber structures. Glued laminated timber and glued solid timber. Requirements. Brussels, Belgium.

Galvez-Martos, J.L., Styles D., Schoenberger H., Zeschmar-Lahl B. (2018). "Construction and demolition waste best management practice in Europe." Con. Build. Mater. 136, 166-178.

Komnitsas, K., Zaharaki, D., Vlachou, A., Bartzas, G. and Galetakis, M. (2015). "Effect of synthesis parameters on the quality of construction and demolition wastes (CDW) geopolymers." Adv. Powder Technol. 26,368-376.

NHBC Foundation (2016). Modern methods of construction. Views from the industry. Milton Keynes, UK.

NHBC Foundation (2018). Modern methods of construction. Who's doing what? Milton Keynes, UK.

Reig, L., Tashima, M.M., Borrachero, M.V., Monzo, J., Cheeseman, C.R. and Paya, J. (2013). "Properties and microstructure of alkali-activated red clay brick waste." Con. Build. Mater. 43,98-106.

REuse and REcycling of CDW materials and structures in energy efficient pREfabricated elements for building Refurbishment and construction (RE4) project (2018). http://www.re4.eu/.

Robayo-Salazar, R.A., Rivera, J.F. and Mejia de Gutierrez, R. (2017). "Alkaliactivated building materials made with recycled construction and demolition wastes." Con. Build. Mater. 149,130-138.

Sassi, P. (2002). "Classification in relation to dismantling, reusing and recycling." Sust. Build. Indepen. J Build. Env. 4,22-26.

Wijayasundara, M., Mendis, P. and Crawford, R.H. (2017). "Methodology for the integrated assessment on the use of recycled concrete aggregate replacing natural aggregate in structural concrete." J. Clean. Prod. 166,321-334.

Wijayasundara, M., Mendis, P. and Crawford, R.H. (2018). "Integrated assessment of the use of recycled concrete aggregate replacing natural aggregate in structural concrete." J. Clean. Prod. 174,591-604.

Wong, C.L., Mo, K.H., Yap, S.P. and Johnson Alengaram, U. (2018). "Potential use of brick waste as alternative concrete-making materials: A review." J Clean. Prod. 195,226-239. 
